\title{
Diabetic Neuropathy: Distribution Pattern Revisited
}

\author{
Osamu Takahashia ${ }^{a}$ Ryuji Sakakibara ${ }^{b}$ Fuyuki Tateno $^{\mathrm{b}}$ Yosuke Aibab $^{\mathrm{b}}$ \\ ${ }^{a}$ Clinical Physiology Unit, Sakura Medical Center, Toho University, Sakura, Japan; \\ bNeurology, Internal Medicine, Sakura Medical Center, Toho University, Sakura, Japan
}

\section{Keywords}

Elderly · Diabetes · Neuropathy · Multiple mononeuropathy $\cdot$ Atherosclerosis

\begin{abstract}
It is not well known which of the common neuropathic distribution patterns in diabetes might suggest underlying mechanisms. To examine this question, we present data from a nerve conduction study (NCS). Irrespective of symptoms, we enrolled 323 type 2 diabetic patients (206 men, 117 women; mean age 64.1 years [51-79]; duration 12.0 years [5-19]; HbA1C 8.7\% [5.112.1]; half [ $n=142]$ untreated). NCS was performed for the following patterns: mononeuropathy (unilateral [MNU], bilateral [MNB]), multiple mononeuropathy (MMN), and polyneuropathy (PN). In 266 patients, we performed atherosclerosis tests: cardio-ankle vascular stiffness index (CAVI) and carotid ultrasonography. Neuropathy was observed in 235, and in 88 it was not observed; the latter then served as the control group. The most common pattern was MMN (26\%), followed by MNB (18\%), PN (16\%), and MNU (12\%). A combination of demyelination and axonal damage was revealed. Longer duration of diabetes compared with controls (8.6 years) was associated with MNB (12.5 years), MMN (14.8 years), and PN (17.4 years) $(p<0.05)$. $\mathrm{HbA} 1 \mathrm{C}$ was associated with $\mathrm{PN}(p<0.05)$. Atherosclerosis risks were associated with MNB,
\end{abstract}




\section{Case Reports in Neurology}

Case Rep Neurol 2020;12:160-164

2020 The Author(s). Published by S. Karger AG, Basel www.karger.com/crn

Takahashi et al.: Diabetic Neuropathy Pattern

MMN, and PN ( $p$ < 0.05). Our study results indicated that (multiple) mononeuropathy is the most common distribution pattern in diabetes.

(C) 2020 The Author(s)

Published by S. Karger AG, Basel

\section{Introduction}

While diabetic neuropathy (DN) has several clinical, electrophysiologic distribution patterns (polyneuropathy, PN [symmetric, distal], multiple mononeuropathy [asymmetric, distal/proximal], mononeuropathy [focal], etc.), it remains uncertain which pattern is the most common [1-4]. To examine this question, we present data of clinical, electrophysiologic DN patterns with atherosclerosis tests.

\section{Methods}

We enrolled 323 type 2 diabetes subjects. All were referred for neuropathy screening irrespective of symptoms. The diagnostic criteria of type 2 diabetes and DN conformed to the published criteria [1,2]. Subjects were 206 men and 117 women: most were elderly (mean age 64.1 years [51-79 years]); mean disease duration of 12.0 years (5-19 years); mean HbA1C $8.7 \%(5.1-12.1 \%)$. Half of the subjects $(n=142)$ were untreated; the rest $(n=181)$ were receiving oral sulphonylurea, thiazolidine derivatives, dipeptidyl peptidase-4 inhibitors, and/or insulin, and had $\mathrm{HbA1C}$ values ranging from 5.1 to 8.9\%. Other than diabetes, none had comorbid diseases that might contribute to neuropathy (e.g., alcohol, vitamin deficiency, drugs [chemotherapy, etc.], toxins [lead, etc.], uremia, collagen/granulomatous diseases, neoplasm, or history of familial neuropathies) [1-3]. All patients were able to walk independently. A total of $28 \%$ of patients had numbness, pain, etc., in the extremities.

In order to explore the diversity of neuropathy, we defined DN by nerve conduction study (NCS), irrespective of subjective symptoms. We performed a standard nerve conduction study NCS [2] in all patients with an electromyography computer (Neuropack M2; Nihon Kohden Inc., Tokyo, Japan) on both sides of the median, ulnar, tibial, peroneal, and sural nerves to identify any abnormalities of distal latencies, conduction velocity, F-wave latency, or evidence of conduction block (all indicating demyelination); or abnormalities of compound muscle action potential or sensory nerve action potential (indicating axonal damage) [2]. The patterns of neuropathies were classified as mononeuropathy (focal, uni- or bilateral - a typical example is uni- or bilateral carpal tunnel syndrome - excluding cranial in the present study), multiple mononeuropathy (often asymmetric, sometimes proximal), and PN (symmetric, distal) [2-4]. For PN, we used Dyck's criteria 7, i.e., a total of 5 nerve conduction deviates [2]. Demyelination and axonal damage were determined by the threshold of NCS as described previously [5]. We also performed atherosclerosis tests: (1) cardio-ankle vascular stiffness index (CAVI) [6]; and (2) duplex carotid ultrasonography. CAVI is an atherosclerosis measure using a pulse wave velocity but independent from blood pressure (VaSera; Fukuda Denshi Inc., Tokyo, Japan) [6]. We obtained intima-media thickness (IMT) and the plaque score (PS) of the carotid arteries by EUB-525 (Hitachi, Inc., Tokyo, Japan). Data were analyzed by Student's $t$ test and MannWhitney U-test. 


\section{Case Reports in Neurology}

\section{Results}

Among 323 referred subjects, 235 patients (73\%) had DN. Subjective symptoms (numbness, pain, etc.) were noted in 18-52\% (39\% overall) among those with NCS-determined DN; no subjective symptoms were noted in those without DN $(28 \%$ of subjects had subjective symptoms). The rest (88 subjects) were treated as the controls. Regarding the pattern of neuropathy, the most common was multiple mononeuropathy (26\%), followed by bilateral mononeuropathy (18\%), PN (16\%), and unilateral mononeuropathy (12\%); altogether mononeuropathies [unilateral, bilateral, and multiple] comprised $56 \%$ of cases (Table 1a). Regarding the type of neuropathy, mononeuropathy cases tended to have demyelination, while PN cases tended to have a combination of demyelination and axonal damage, although none of these differences reached statistical significance. Regarding the duration of diabetes, duration in control subjects (8.6 years) was shorter than that in MNB (12.5 years), MMN (14.8 years), and PN (17.4 years) ( $p<0.05,0.01$ ) (Table 1b). Concerning the severity of diabetes, compared with HbA1C in control subjects, that in PN alone was significantly increased $(p<$ 0.05). In terms of atherosclerotic markers, compared to CAVI, IMT and PS in control subjects, those in MNB, MMN, and PN were significantly increased $(p<0.05,0.01)$ (Table 1b).

\section{Discussion}

The question of which clinical, electrophysiologic pattern is the most common in DN remains to be clarified. Our results showed that the most common was multiple mononeuropathy (26\%), followed by bilateral mononeuropathy (18\%), PN (16\%), and unilateral mononeuropathy $(12 \%)$. Of these, PN mainly represents metabolic disorders due to hyperglycemia such as polyol shunting, accumulation of advanced glycation end products, etc. [2, 3]. In contrast, mono/multiple-neuropathy mainly represents mechanical compression or entrapment due to focal ischemia, inflammation, etc. [2, 7-10]. Our study results also showed that the duration of diabetes was shortest in the control group (8.6 years), longer in unilateral mononeuropathy (9.1 years), bilateral mononeuropathy (12.5 years), and multiple mononeuropathy (14.8 years), and longest in PN (17.4 years) $(p<0.01)$. Risks of atherosclerosis were not associated with mononeuropathy, but were closely associated with multiple mononeuropathy and PN $(p<0.01)$. However, this association might simply reflect the duration of diabetes, since the relation was noted only in groups with duration $>10$ years. These observations suggest that DN might start as mononeuropathy, and then develop into multiple mononeuropathy and ultimately PN.

This study has several limitations. We analyzed NCS data. However, NCS represents thick myelinated nerve fiber function alone. Small fiber sensory neuropathy and autonomic neuropathy can still occur in isolation. Also, we performed this study with a small number of patients, no prospective study, no stratification by subjective symptom, and no metabolically normal control. In order to confirm the DN progression suggested by our findings, prospective, single large cohort studies will be necessary.

In conclusion, our study results indicate that (multiple) mononeuropathy is the most common distribution pattern in DN. 


\section{Statement of Ethics}

All subjects provided written informed consent to publish their case (including images), and the study protocol was approved by the Ethics Committee of the Sakura Medical Center, Toho University.

\section{Disclosure Statement}

The authors have no conflicts of interest to declare.

\section{Funding Sources}

No funding was received.

\section{Author Contributions}

Osamu Takahashi: acquisition, analysis, and interpretation of data. Ryuji Sakakibara: study concept and design, acquisition of subjects and/or data, analysis and interpretation of data, and preparation of the manuscript. Fuyuki Tateno: acquisition of subjects and/or data. Yosuke Aiba: acquisition of subjects and/or data.

\section{References}

1 Ziegler D, Rathmann W, Dickhaus T, Meisinger C, Mielck A; KORA Study Group. Prevalence of polyneuropathy in pre-diabetes and diabetes is associated with abdominal obesity and macroangiopathy: the MONICA/KORA Augsburg Surveys S2 and S3. Diabetes Care. 2008 Mar;31(3):464-9.

2 Dyck PJ, Albers JW, Andersen H, Arezzo JC, Biessels GJ, Bril V, et al.; Toronto Expert Panel on Diabetic Neuropathy. Diabetic polyneuropathies: update on research definition, diagnostic criteria and estimation of severity. Diabetes Metab Res Rev. 2011 Oct;27(7):620-8.

3 Dyck PJ, Clark VM, Overland CJ, Davies JL, Pach JM, Dyck PJ, et al. Impaired glycemia and diabetic polyneuropathy: the OC IG Survey. Diabetes Care. 2012 Mar;35(3):584-91.

4 Committee of the Japan Diabetes Society on the Diagnostic Criteria of Diabetes Mellitus; Seino Y, Nanjo K, Tajima N, Kadowaki T, Kashiwagi A, Araki E, Ito C, Inagaki N, Iwamoto Y, Kasuga M, Hanafusa T, Haneda M, Ueki K. Report of the committee on the classification and diagnostic criteria of diabetes mellitus. J Diabetes Investig. 2010;1:212-28.

5 Sawai S, Sakakibara R, Uchiyama T, Liu Z, Yamamoto T, Ito T, et al. Acute motor axonal neuropathy presenting with bowel, bladder, and erectile dysfunction. J Neurol. 2007 Feb;254(2):250-2.

6 Suzuki J, Sakakibara R, Tomaru T, Tateno F, Kishi M, Ogawa E, et al. Stroke and cardio-ankle vascular stiffness index. J Stroke Cerebrovasc Dis. 2013 Feb;22(2):171-5.

7 Said G, Lacroix C, Lozeron P, Ropert A, Planté V, Adams D. Inflammatory vasculopathy in multifocal diabetic neuropathy. Brain. 2003 Feb;126(Pt 2):376-85.

8 Duru NS, Acar H, Ayta S, Elevli M. Bilateral carpal tunnel syndrome in a child with type 1 diabetes mellitus. Neurol India. 2010 Jan-Feb;58(1):136-7.

9 Rangel MA, Baptista C, Santos F, Real MV, Campos RA, Leite AL. Acute mononeuropathy in a child with newly diagnosed type 1 diabetes mellitus. J Pediatr Endocrinol Metab. 2015 Mar;28(3-4):341-4. 
10 Pourmemari MH, Shiri R. Diabetes as a risk factor for carpal tunnel syndrome: a systematic review and meta-analysis. Diabet Med. 2016 Jan;33(1):10-6.

Table 1. Nerve conduction study findings in diabetic patients a Patterns and types of diabetic neuropathy

\begin{tabular}{|c|c|c|c|c|c|c|c|c|}
\hline \multirow[b]{2}{*}{ Normal/none } & \multirow{2}{*}{$\begin{array}{l}\text { Demye- } \\
\text { lination } \\
(\%) \\
0\end{array}$} & \multirow{2}{*}{$\begin{array}{l}\text { Axonal } \\
\text { damage } \\
(\%) \\
0\end{array}$} & \multicolumn{4}{|c|}{$\begin{array}{l}\text { Demyelination Patients (\%) } \\
\text { + axonal } \\
\text { damage }(\%)\end{array}$} & \multicolumn{2}{|c|}{$\begin{array}{r}\text { Patients, } n \text { Subjective } \\
\text { symptom } \\
(\%)\end{array}$} \\
\hline & & & 0 & 27 & & & 88 & 0 \\
\hline Mononeuropathy (unilateral) & 60.5 & 18.4 & 21.1 & 12 & 30 & 56 & 38 & 18 \\
\hline Mononeuropathy (one nerve, bilateral affection) & 50.8 & 5.1 & 42.4 & 18 & 30 & 56 & 59 & 27 \\
\hline Multiple mononeuropathy & 38.8 & 11.8 & 49.4 & 26 & & 56 & 85 & 48 \\
\hline Distal polyneuropathy & 9.4 & 5.7 & 84.9 & 16 & & & 53 & 52 \\
\hline
\end{tabular}

b Relationship between diabetic neuropathy and disease duration, severity (HbA1C), and atherosclerotic markers

\begin{tabular}{|c|c|c|c|c|c|c|c|}
\hline & \multicolumn{2}{|l|}{ Neuropathy } & \multicolumn{2}{|l|}{ Diabetes } & \multicolumn{3}{|c|}{ Atherosclerotic markers } \\
\hline & \multicolumn{2}{|l|}{ Patients } & \multirow[t]{3}{*}{$\begin{array}{l}\text { mean duration } \\
\text { (years) }\end{array}$} & HbA1c & $\begin{array}{l}\text { CAVI (age ad- } \\
\text { justed) }\end{array}$ & $\begin{array}{l}\text { carotid echo- } \\
\text { graphy }\end{array}$ & $\begin{array}{l}\text { carotid } \\
\text { echo- } \\
\text { graphy }\end{array}$ \\
\hline & \multirow{2}{*}{\multicolumn{2}{|c|}{ (who underwent atherosclerotic tests) }} & & \multirow[t]{2}{*}{$(\%)$} & abnormality & IMT $>0.9 \mathrm{~mm}$ & PS $>1$ \\
\hline & & & & & $(\%)$ & $(\%)$ & $(\%)$ \\
\hline \multirow[t]{5}{*}{ Pattern } & normal/none & 74 & 8.6 & 8.7 & 38.7 & 35.1 & 7 \\
\hline & mononeuropathy (unilateral) & 30 & 9.1 & 8.6 & 20.8 & 40 & 12 \\
\hline & mononeuropathy (one nerve, bilateral affection) & 47 & $12.5^{*}$ & 8.3 & 48.5 & $67.7^{* *}$ & $14.7^{* *}$ \\
\hline & multiple mononeuropathy & 69 & $14.8^{*}$ & 8.7 & 54.9 & 47 & $27.5^{* *}$ \\
\hline & distal polyneuropathy & 46 & $17.4^{* *}$ & $9.7^{* *}$ & $66.7^{* *}$ & $60^{*}$ & $27.5^{* *}$ \\
\hline \multirow[t]{3}{*}{ Type } & demyelinating & 73 & $13^{*}$ & 8.9 & 42.6 & 47.6 & $22.2^{* *}$ \\
\hline & axonal damage & 16 & $13.4^{*}$ & 7.5 & 54.5 & 30 & 20 \\
\hline & $\begin{array}{l}\text { demyelinating } \\
\text { +axonal damage }\end{array}$ & 103 & $14.7^{* *}$ & 8.9 & $56.9 *$ & $62.4^{* *}$ & $22.1^{* *}$ \\
\hline
\end{tabular}

